casts. Effective visuals embodied theories, even hypotheses. Clark shows how tree diagrams and image series communicated understandings of descent, but accusations of guessing pushed Osborn to pretend they illustrated unvarnished facts. He commissioned murals and book covers that ennobled cave-painting Cro-Magnon man (as pictured, left), but well-known sequences confirmed the connection to brutish apemen more strongly than he could deny. Cartoons played on images of the Scopes 'monkey trial', and people joked about missing links.

God - or Gorilla hints at a larger clash of visual cultures between modernists and fundamentalists: Neanderthals versus Adam and Eve, church frescoes depicting ascent from protozoa against a 'picturable God'. That would be a great topic for further research, which would need to pay religious icons more attention, but this highly readable book is valuable as it stands. It is also timely. The 1920s shaped pictures of evolution, and of evolutionary debate, that are still in our heads. As biologists work with illustrators to communicate science, and creationists attack textbook icons, it is helpful to reflect on the struggles of that decisive decade.

Nick Hopwood is in the Department of History and Philosophy of Science, University of Cambridge, Cambridge CB2 3RH, UK. e-mail:ndh12@cam.ac.uk

\title{
Drawing from Darwin
}

\author{
Endless Forms: Charles Darwin, Natural \\ Science and the Visual Arts \\ Yale Center for British Art, New Haven, \\ Connecticut, USA \\ Until 3 May 2009 \\ Fitzwilliam Museum, Cambridge, UK \\ From 16 June until 4 October 2009
}

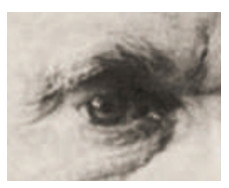

How many geneticists today spend their free time reading about aesthetics? How many painters keep abreast of the latest developments in geology? I would wager precious Darwin200 few. But things were different in the nineteenth century: artists shaped the way scientists saw nature, and thought deeply about how science changed the nature of art.

The exhibition Endless Forms explores Charles Darwin's influence on the artists of his day, and shows how paintings and photographs helped to shape Darwin's understanding of nature. Some 200 works are displayed in this collaboration between the Yale Center for British Art in New Haven, Connecticut, where the exhibition is located until May, and the Fitzwilliam Museum in Cambridge, UK, where it moves in June.

The exhibit does a good job of showing how differently people saw the world at the dawn of the nineteenth century. Nature was replete with signs of divine design. A painting of Noah's flood was considered historical art. Yet Darwin was able to learn a great deal from art of this time, whether he was studying illustrations of geological formations or marvelling at the paintings of French-American naturalist John James Audubon, who Darwin met as a teenager.

As Darwin developed as a scientist, he made some modest art of his own. On his journeys in South America, he painted the rock strata of the Andes in watercolour. On his return to the United Kingdom, he began to scribble odd little tree diagrams in his notebooks - a visual expression of his great epiphany that species are related through common descent. Darwin worked closely with artists to illustrate his books. This may surprise readers of $\mathrm{On}$ the Origin of Species - a book with a single illustration showing the branching of species. But his other books were lavishly illustrated. The exhibition includes a gorgeous fold-out picture of a fossilized sloth skull from The Zoology of the Voyage of H.M.S. Beagle, along with engravings of elegant orchids, birds with luxurious

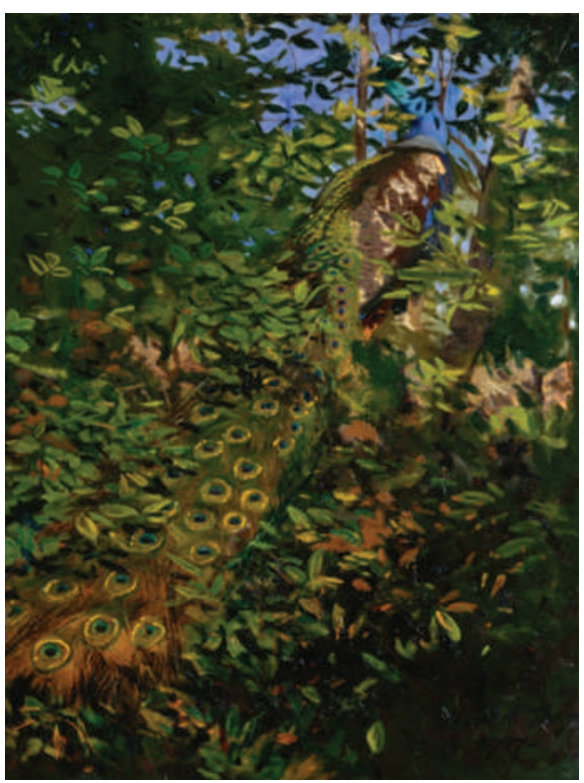

Not all artists agreed with Charles Darwin's theory that peacocks use their bright tail to attract a mate. plumage and other creatures from later books.

Darwin was at the cutting edge of visualization. His 1872 work The Expression of the Emotions in Man and Animals was one of the first books ever to be illustrated with photographs including pictures of faces distorted by electric currents, produced by the work of French physician Guillaume Duchenne. Endless Forms includes Darwin's personal copies of these photographs, which are disturbingly rich in detail.

Darwin did not use art simply to illustrate his ideas, but to investigate them. In Duchenne's pictures he saw evidence that human expressions of surprise or fear were reflexes triggered by electrical activity, in the same way that a dog is made to snarl. He corresponded with painters of animals, recognizing their deep knowledge of expressions on non-human faces. Indeed, the very notion of beauty was something Darwin wanted to explain: the beauty of orchids actually masked a complex contrivance for getting pollen onto insects; the beauty of an Argus pheasant's feathers was the result of sexual selection.

Artists paid close attention to Darwin. They modelled faces after the ones in his illustrations. They replaced sentimental scenes of nature with bleaker portraits of the struggle for survival. The US artist Abbott Handerson Thayer used his art to explore the subtleties of animal camouflage. One of his most famous paintings, Peacock in the Woods (1907; pictured), is a rebuke to Darwin; Thayer refused to believe that brightly coloured feathers were a conspicuous display for attracting a mate, so he showed a peacock almost completely hidden in a dappled forest.

Endless Forms captivates the eye while getting the science right. It deserves great credit for not shying away from difficult subjects: some wrongly took it as justification to elevate whites over other races, cloaking their freakshow voyeurism in the guise of anthropology. Not all of the ties to Darwin in the exhibition are convincing. Some beautiful paintings by impressionists are included, but the links are tenuous - Paul Cézanne was friends with a Darwinian archaeologist, for example, and Claude Monet was careful about painting rock formations accurately.

The exhibition presents evidence that undermines the case for Darwin's universal influence. Even before Darwin published On the Origin of Species in 1859, people were seeing nature and the history of life in new ways. They were fascinated by the massive dinosaur reconstructions at London's Crystal Palace in 1854, for example. By the end of the nineteenth century, the world looked very different, but it was not Darwin alone who helped change the way we see. Carl Zimmer is author of Evolution: The Triumph of an Idea.

e-mail: carl@carlzimmer.com 